\title{
Numerical Investigation of the Leakage and Rotordynamic Characteristic for a Short Staggered Labyrinth Seal
}

\author{
Minglei Zhong \\ Department of Thermal Engineering, Tsinghua University, Beijing 100084, PR China \\ Corresponding author:1xs78@139.com
}

\begin{abstract}
Short staggered labyrinth seals are widely used in high pressure cylinder shroud seals of steam turbines. They are good at restricting the leakage flow but do not respond well to rotordynamics and often lead to turbomachine instabilities. A numerical investigation into the leakage and rotordynamic characteristics of a short staggered labyrinth seal is carried out in this paper, concerning effects of pressure ratio, inlet preswirl, rotational speed, seal clearance and whirling frequency, using both the whirling rotor method and the multiple frequencies transient simulation method. The numerical model is verified by experimental data. The result shows that the staggered labyrinth seals have a similar but not identical leakage and rotordynamic performance compared with that of teeth-on-stator see-through labyrinth seals. The cross-coupled stiffness can be reduced by decrease inlet swirl with considering the factor of rotational speed, which can significantly benefit the stability of rotor system.
\end{abstract}

\section{Introduction}

Labyrinth seals are commonplace in turbomachinery to reduce leakage through rotor-stator clearances from high pressure regions to low pressure regions. This is a necessity to enhance the thermodynamic performance of modern turbomachinery, since the leakage flows are one of the main sources of losses. Along with leakage performance, the importance of rotordynamic assessment for noncontact seals is well recognized. Many researchers have shown that labyrinth seals used in high-speed, high-power-density applications can provoke nonsynchronous self-excited vibrations and often lead to turbomachine instabilities.

In order to estimate the instability of rotor systems, researchers have developed several bulk-flow models to calculate the rotordynamic coefficients of labyrinth seals, such as Childs $[1,2]$ et al. The primary advantage of these bulk-flow models is that they can predict the rotordynamic coefficients with efficient computational cost. However, these models require the empirical correction, such as friction factors that may change for varying applications and geometry, to have the analysis predictions match the experimental results.

Recently computational fluid dynamics (CFD) has obtained great development such as the schemes [3-5], large eddy simulation $[6,7]$ and detached eddy simulation $[8,9]$, and the capability of CFD has been shown for simulation flows of small clearances such as bearings $[10,11]$ and seals [12-14]. Therefore, CFD programs and software are now gradually displacing the bulk-flow approach in predicting the rotordynamic coefficients of annular gas seals. Compared to the experimental measurements and bulk-flow methods, the CFD method can offer a great deal of insight for understanding the fluid dynamics of the annular gas seal flows and developing new seal design. Currently, the CFD analysis for the rotordynamic characteristics of the labyrinth seal have been carried out by many authors. Huang researched rotordynamic characteristics [12], coupled fluid-solid vibration [14], and developed a non-linear model [13] of seals by CFD. Moore [15] studied two labyrinth seals using a specially developed CFD code named SCISEAL. Hirano [16] applied CFD technique to a compressor eye seal leakage and rotordynamic simulation with commercial CFD program CFX-TASCflow. Pugachev [17, 18] used CFD software ANSYS CFX, studied the rotordanymic performance of a short staggered labyrinth seal, and compared the results to experimental data.

In practice, the short staggered labyrinth seals are widely used in high pressure cylinder shroud seals of steam turbine, since the physical dimensions are limited. In the earlier research, most work are concentrated on leakage and rotordynamic performance of see-through labyrinth seals, while few work is about staggered labyrinth seal. Therefore, a detailed study of the short staggered labyrinth seals is quite essential and significant. In this paper, a short staggered labyrinth seal is studied to find out the influence of pressure ratio, inlet swirl, rotating speed, seal clearance and whirling frequency to leakage and rotordynamic performance.

\section{Numerical model}

\subsection{Linear rotordynamic model}

(C) The Authors, published by EDP Sciences. This is an open access article distributed under the terms of the Creative Commons Attribution License 4.0 (http://creativecommons.org/licenses/by/4.0/). 
The influence of the seal on rotordynamics is described by the seal's stiffness $\mathrm{K}$, and damping $\mathrm{C}$ coefficients. For small motion about a centered position (x-axis), these coefficients appear when linearizing the aerodynamic force which arises due to the squeezed air film in the seal:

$$
-\left(\begin{array}{l}
F_{y} \\
F_{z}
\end{array}\right)=\left[\begin{array}{ll}
K & k \\
-k & K
\end{array}\right]\left(\begin{array}{l}
y \\
z
\end{array}\right)+\left[\begin{array}{ll}
C & c \\
-c & C
\end{array}\right]\left(\begin{array}{l}
\dot{y} \\
\dot{z}
\end{array}\right)
$$

Assuming a circular whirl orbit around the seal center and a small shaft eccentricity e, as shown in Figure 1, the linear rotordynamic model of Eq. (1) can be written in a new coordinate system aligned with vectors normal and tangential to the shaft surface as

$$
\begin{aligned}
& F_{r} / e=-K-c \cdot \Omega \\
& F_{t} / e=k-C \cdot \Omega
\end{aligned}
$$

According to Eq. (2), knowing aerodynamic forces acting in the seal at different operating conditions one can determine rotordynamic coefficients. The cross-coupled stiffness $\mathrm{k}$ and direct damping $\mathrm{C}$ terms are of particular interest. The cross-coupled stiffness is governed by the tangential force $F_{t}$ which contributes to the destabilizing of the rotor system. The direct damping reflects the capability to suppress severe vibrations. A negative value of the direct stiffness also contributes to instability. In this instance the radial force $F_{r}$ is acting in the direction of the rotor excursion and tries to increase the rotor eccentricity.

However, information on the stiffness of the whole rotor system is necessary to judge the effect of the seal direct stiffness on rotordynamics. The assessment of the stability performance of a seal can be evaluated by the whirlfrequency ratio, as defined in Eq. (3). It is the ratio between the destabilizing force due to the cross-coupled stiffness $\mathrm{k}$ and stabilizing force due to the direct damping $\mathrm{C}$. A lower $\Omega_{w}$, which means a lower cross-coupled stiffness coefficient or a bigger direct damping coefficient, is expected to obtain better stability of the rotor system.

$$
\Omega_{w}=k /(\omega C)
$$
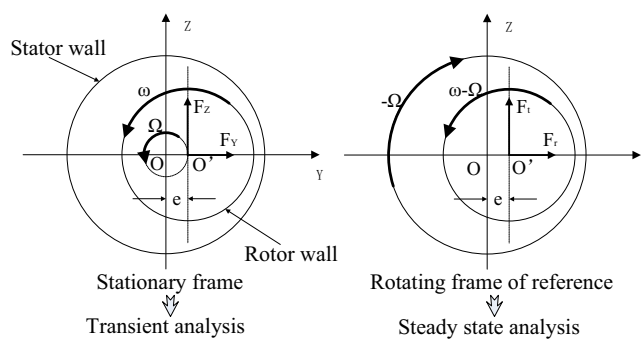

Fig. 1. Motion Model of Seal-Whirling Rotor in Stationary and Rotating Frame.

\subsection{Identification of rotordynamic coefficients}

There are two methods used in this paper to calculate rotordynamic coefficients which are appropriate for the CFD analysis. They are described as below.

The whirling rotor method is based on CFD calculations in a rotating frame, as shown in Figure 1(b). the rotor is supposed to whirl with a circular orbit and small amplitude around the seal centerline. The dynamic behavior of the seal is modeled by steady-state calculations. Rotational speed in the rotating frame of reference is the difference between the speed in the stationary frame of reference ( $\omega$ for rotor and zero for stator) and the rotor whirl speed:

$$
\omega^{r}=\omega-\Omega
$$

The procedure of calculating four rotordynamic coefficients involves at least two CFD solutions at different rotor whirl speeds. The rotordynamic coefficients are determined from the linear interpolation of the force components that are functions of the whirl speed.

The transient simulation method is the most computationally expensive technique to determine rotordynamic coefficients, but it can simulate any user defined complex movements. Li [19] has presented a 3D transient CFD method based on the multi-frequency elliptical whirling orbit model. In the present paper, a revised model based on this multi-frequency approach is developed. To obtain the rotordynamic coefficients, the first step in the present numerical analysis is to develop the equations of whirling motion for the rotor surface. Here a y-direction sine curve to the rotor movement is assigned, as described below:

$$
y=\sum_{i} A_{i} \sin \left(\Omega_{i} t\right), z=0
$$

During the calculation, the computational grid is deformed at every time step according to the new position of the shaft. The capability of mesh deformation is provided in ANSYS CFX software. In this approach, the shaft surface rotates around its center with a rotational speed $\omega$, and the stator wall keeps still. 
For the multi-frequency model in the present paper, the response forces $\left(F_{y}, F_{z}\right)$, rotor motions $(y, z)$, and rotor velocity $(\dot{y}, \dot{z})$ in Eq. (1) are multi-frequency signals that contain the same frequency components, but different initial phases. Therefore, to obtain the rotordynamic coefficients for each frequency component, it is necessary to transform Eq. (1) into the frequency domain expression given by Eq. (6) using the FFT.

$$
\begin{aligned}
& -F_{y}^{F F T}=(K+j \Omega C) y^{F F T}+(k+j \Omega c) z^{F F T} \\
& -F_{z}^{F F T}=-(k+j \Omega c) y^{F F T}+(K+j \Omega C) z^{F F T}
\end{aligned}
$$

where $j=\sqrt{-1},\left(y^{F F T}, z^{F F T}\right)$ and $\left(F_{y}^{F F T}, F_{z}^{F F T}\right)$ are the frequency domain components of the relative displacement and the response forces after the transformation. Therefore, introducing the y-direction sine curve rotor movement assumption, Eq. (6) can be written into a new form:

$$
-\left(\begin{array}{c}
F_{y}^{F F T} \\
F_{z}^{F F T}
\end{array}\right)=y^{F F T}\left(\begin{array}{c}
K+j \Omega C \\
-(k+j \Omega c)
\end{array}\right)
$$

Once the force impedances are obtained through the transient solutions in this paper, rotordynamic coefficients are calculated by solving Eq. (7) and separating the right-side array into real and imaginary parts, as defined in Eqs.(8)-(11).

$$
\begin{aligned}
& K=-\operatorname{Re}\left(F_{y}^{F F T} / y^{F F T}\right) \\
& k=\operatorname{Re}\left(F_{z}^{F F T} / y^{F F T}\right) \\
& C=-\operatorname{Im}\left(F_{y}^{F F T} / y^{F F T}\right) / \Omega \\
& c=\operatorname{Im}\left(F_{z}^{F F T} / y^{F F T}\right) / \Omega
\end{aligned}
$$

\subsection{Numerical model}

In this paper, a short staggered three-tooth-on-stator labyrinth seal model is utilized as the computational model. The seal geometrical parameters and operational conditions in this work are based on the experimental and computational results published by Pugachev $[17,18]$.

The geometry of the seal typical for blade tip and shroud seal locations, is shown in Figure 2. The shaft band height is $3 \mathrm{~mm}$ and the length is $6 \mathrm{~mm}$. The tooth width is $1 \mathrm{~mm}$, with a $0.3 \mathrm{~mm}$ width at the tip, and the tooth taper is $75 \mathrm{deg}$.

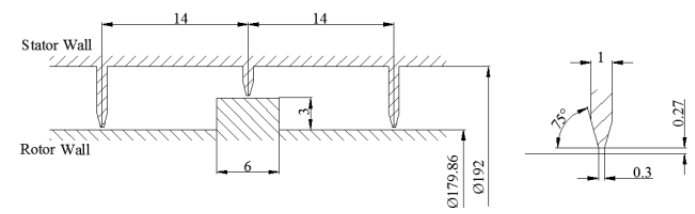

Fig. 2. Geometry of the Three-tooth-on-stator Staggered Labyrinth Seal.

A full eccentric 3D CFD model of the seal is constructed in the commercial CFD code ANSYS CFX. Threedimensional structural grids are generated using ANSYS ICEM CFD. Figure 3 shows a cross-sectional plane illustrating distribution of the computational grid. A compressible Reynolds-averaged Navier-Stokes (RANS) analysis with the total energy heat transfer model is considered. Turbulence is simulated using the two-equation k- $\varepsilon$ model, with a scalable wall function. Ideal gas law is used with the assumption of a constant dynamic viscosity. A stable pressure condition is set at the inlet, with specified velocity direction, keeping a constant inlet swirl velocity of $145 \mathrm{~m} / \mathrm{s}$. A static pressure condition is used at the outlet. Two methods are used here to attain the rotordynamic coefficients, as described in section 2.2. The shaft rotate at $750 \mathrm{rpm}$, and whirls around $\mathrm{x}$-axis at $-750 \mathrm{rpm}, 0 \mathrm{rpm}, 750 \mathrm{rpm}$ when using the whirling rotor method. Multiple frequencies from $0-150 \mathrm{~Hz}$ of sinusoid shaft displacement is assigned when using the transient simulation method.

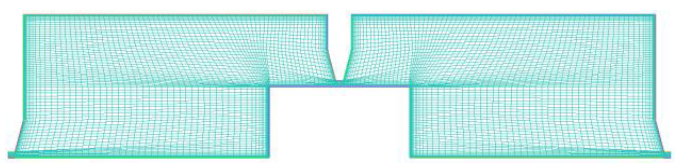

Fig. 3. 2D Cross-sectional Distribution of the Computational Grid.

\section{Verification of numerical model}

Figure 4 is a illustration of the predicted pressure and velocity distribution in the seal cavities. The sharp pressure drop mainly happens at the tip of seal tooth, which is the primary cause for restriction of leakage flows. The rotor band disturbs heavily the flow especially in the second sealing cavity which results in developing of secondary vortices. The 
kinetic energy of the leakage flow is converted into dynamic pressure at locations where the flow hits the wall. This leads to considerable changes in pressure in radial and axial directions within a cavity.

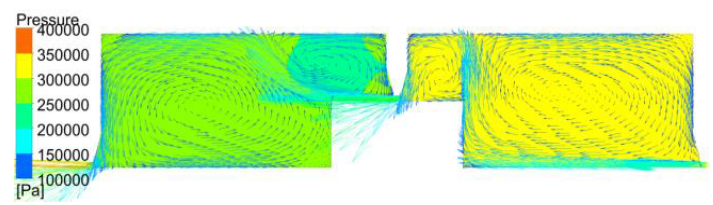

Fig.4. Predicted pressure and velocity distribution in two sealing cavities.

The theoretical rotordynamic coefficients attained by the whirling rotor method is presented in Figure 5, in comparison with experimental result published by Pugachev [17]. Here the linear correlations Pugachev used in his article are followed. That is, there is a linear relationship between direct stiffness with the leakage, and the crosscoupled stiffness with the inflow swirl force(product of leakage and inlet swirl velocity), and the direct and crosscoupled damping with the averaged density. A good conformity between the theoretical and experimental results shown in Figure 5 is a well confirmation of the numerical model.

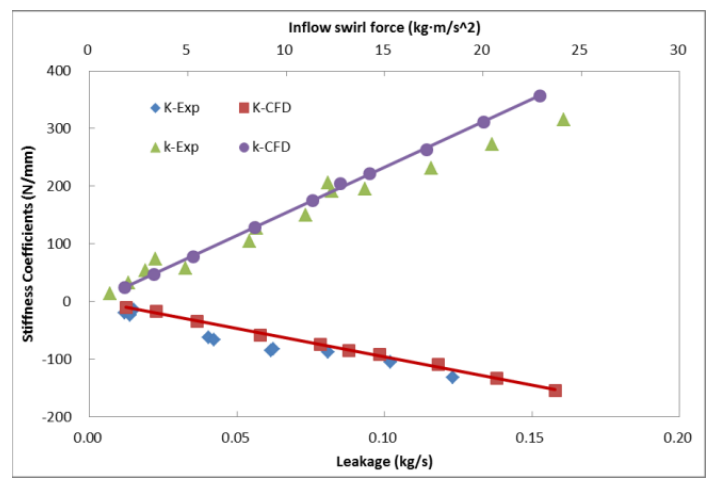

Fig. 5 Experimental and theoretical stiffness coefficients for the short staggered labyrinth seal (direct stiffness versus leakage, crosscoupled stiffness versus inflow swirl force).

\section{Results and discussion}

For see-through labyrinth seals, earlier researches have done lots of experimental and numerical work about the effect of pressure ratio, inlet swirl, rotational speed, seal clearance, and whirling frequency on the leakage and rotordynamic performance. Childs has made prominent contributions and summarized his achievements in his book [20]. Researchers have put forward several useful method [21-25] to solve nonsynchronous self-excited vibrations, such as anti-preswirl method.

In this section a study of the leakage and rotordynamic performance of a short staggered labyrinth seal is carried out, trying to figure out whether the principles of see-through labyrinth seals can be applied to short staggered labyrinth seals.

\subsection{Effects of inlet swirl}

To investigate the effect of inlet swirl on the leakage and rotordynamic characteristics of short staggered labyrinth seal, the whirling rotor method is performed with inlet circular velocity varying from $-150 \mathrm{~m} / \mathrm{s}$ to $150 \mathrm{~m} / \mathrm{s}$, for two inlet pressures $0.4 \mathrm{MPa}$ and $0.15 \mathrm{MPa}$.

Figure 6-8 illustrates correlation of the leakage flow and rotordynamic performance with inlet swirl. The flow rate decreases as the absolute inlet circular velocity increases, while absolute value of direct stiffness and direct damping increase as the inlet swirl getting stronger. The cross-coupled stiffness and cross-coupled damping show an approximately linear relationship with inlet swirl.

This correlation with inlet swirl is consistent with that of see-through labyrinth published by Childs. Hence inlet swirl control is a straightforward way to attain a little cross-coupled stiffness, and to improve rotor system stability. 


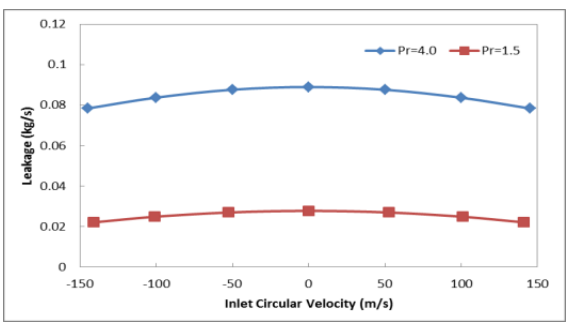

Fig.6. Leakages for inlet circular velocities.

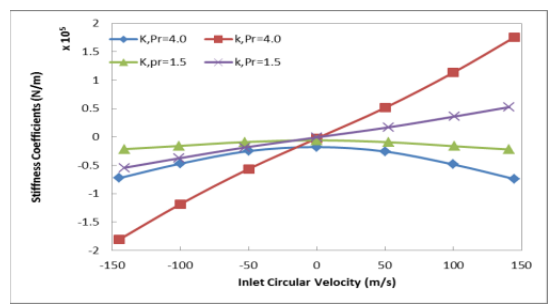

Fig.7. Stiffness coefficients for inlet circular velocities.

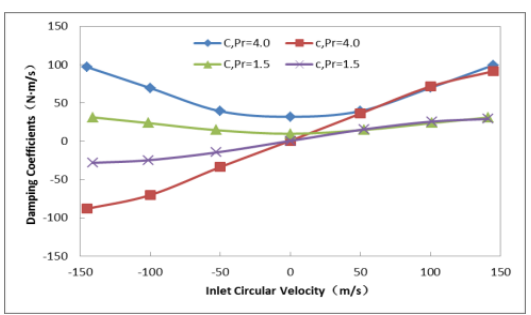

Fig.8. Damping coefficients for inlet circular velocities.

\subsection{Effects of seal clearance}

In order to explore the relationship between seal clearances and seal performance, a variety of cases with different seal clearances and pressure ratios are studied, using the whirling rotor method. A constant inlet circular velocity, $145 \mathrm{~m} / \mathrm{s}$, is guaranteed.

Figure 9 illustrates the leakage performance of the short staggered labyrinth seal as a function of the seal clearance. As expected, the leakage increases as the seal clearance increases. Results of different pressure ratio show a similar trend.

With a seal clearance increase, the cross-coupled stiffness decreases and direct stiffness increases, while the absolute value of direct stiffness decreases, as shown in Figure10. A slight drop of direct damping happens as the seal clearance increases, as shown in Figure11.

These principles are in conformity with the rotordynamic performance of teeth-on-rotor see-through labyrinth. A bigger seal clearance will result in better stability, but will cause a severe leakage. The optimized seal clearance happens when the contradictory compromises.

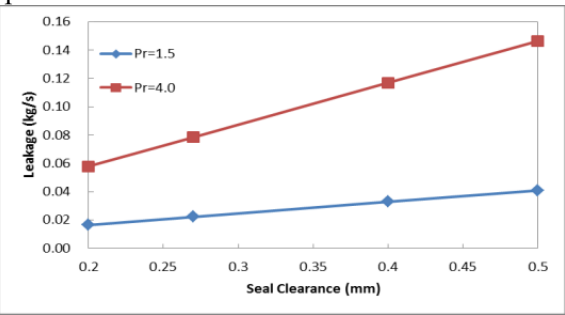

Fig.9. Leakages for seal clearances. 


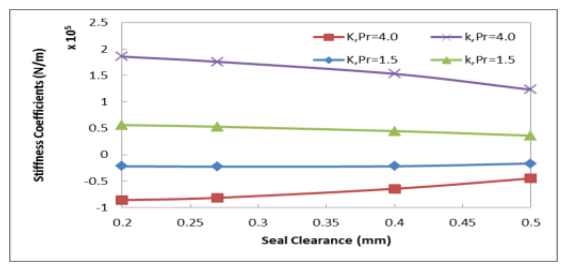

Fig.10. Stiffness coefficients for seal clearances.

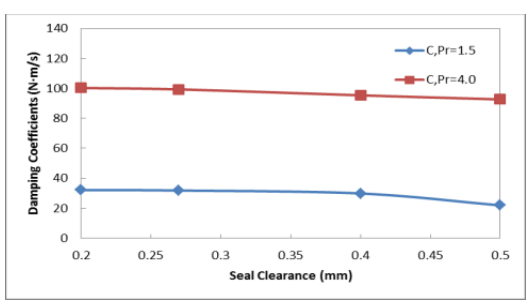

Fig.11. Direct damping coefficients for seal clearances.

\subsection{Effects of rotational speed}

Figure 12-14 illustrate dependence of the leakage flow rate and rotordynamic coefficients versus rotational speed from $5000 \mathrm{rpm}$ to $35000 \mathrm{rpm}$. There is no obvious trend of leakage as rotational speed increases. The direct and crosscoupled stiffness decrease with the increasing rotational speed, while the absolute value of direct stiffness increase because of its negative value. A slight increase of direct damping is observed as the rotational speed increases.

These effects of rotational speed on short staggered labyrinth seal is in consistent with that of see-through labyrinth seal. Especially, the cross-coupled stiffness is obviously effected by the rotational speed.

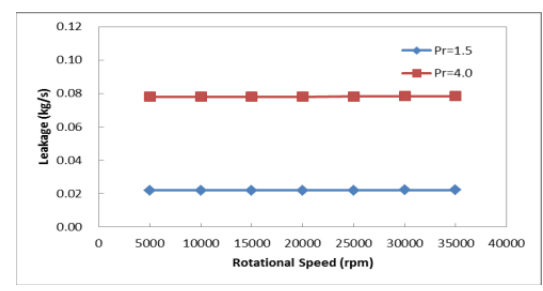

Fig.12. Leakages for rotational speeds.

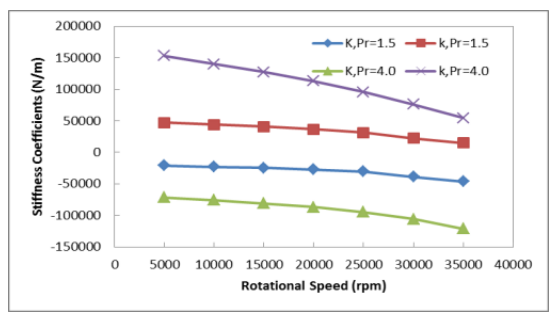

Fig.13. Stiffness coefficients for rotational speeds.

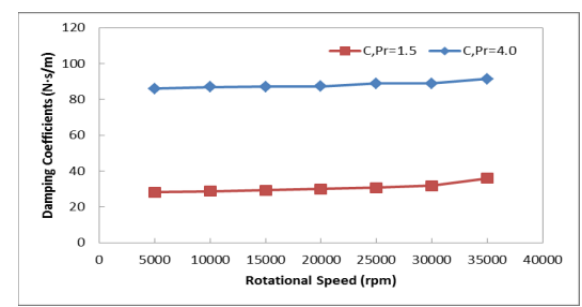

Fig.14. Direct damping coefficients for rotational speeds. 
A multi-frequency transient simulation method is used in this section to investigate frequency dependence of rotordynamic coefficients, since it is convenient to attain several rotordynamic coefficients of different whirling frequencies in a single calculation. Prior studies on see-through labyrinth seal have shown that damping coefficients are independent, while direct stiffness coefficient is frequency dependent and cross-coupled stiffness shows frequency independence out to a frequency of $150 \mathrm{~Hz}$. Other types of seals, such as honeycomb seal, hole-pattern seal, and pocket seal, are known as frequency dependent.

As for short staggered labyrinth seal, Figure 15 shows a frequency independence of cross-coupled and direct stiffness out of a frequency of $50 \mathrm{~Hz}$. Direct and cross-coupled damping seem to be frequency independent, as shown in Figure 16. This phenomenon is similar but not identical to that of see-through labyrinth seal.

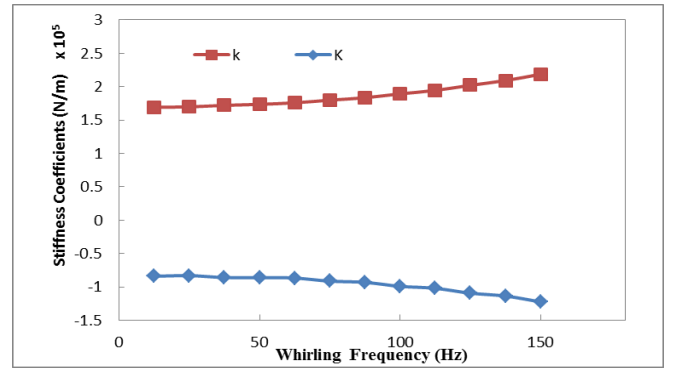

Fig.15. Stiffness coefficient for whirling frequency.

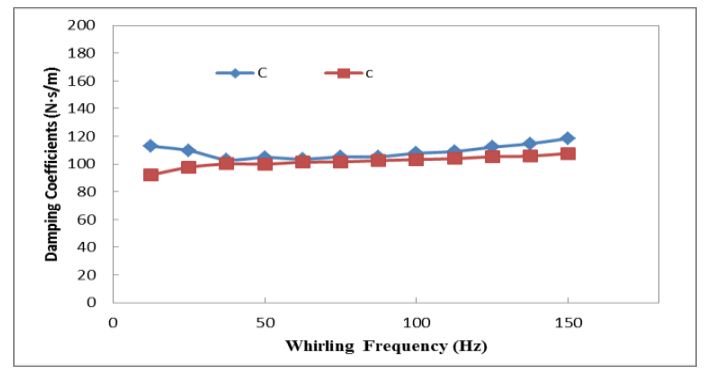

Fig.16. Damping coefficient for whirling frequency.

\section{Conclusions}

A short staggered labyrinth seal is studied in the present paper using two numerical approaches, including the whirling rotor method and the multi-frequency transient simulation method. Verification of these methods is made by comparison with experimental data from Pugachev [17]. A detailed research about the effects of pressure ratio, inlet swirl, rotational speed, seal clearance, and whirling frequency on the leakage and rotordynamic performance is carried out.

(1) Inlet swirl has a great effect on leakage and rotordynamic performance of the short staggered labyrinth seal. The cross-coupled stiffness can be controlled by restricting the inlet circular velocity.

(2) The seal clearance has an obvious influence on leakage and stiffness performance. A bigger seal clearance will result in better stability and severe leakage. Hence compromise is required.

(3) An increase of rotational speed will cause decrease of direct and cross-coupled stiffness.

(4) Cross-coupled and direct stiffness are frequency independent out of a frequency of $50 \mathrm{~Hz}$. Direct and crosscoupled damping seems to be frequency independent.

The result shows that the performance of short staggered labyrinth is similar but not identical to that of see-through labyrinth. Since no evident trend of direct damping is observed in the research, the best way to improve rotor stability lies in controlling the cross-coupled stiffness. A lower inlet circular velocity is expected to restrict cross-coupled stiffness and avoid rotor system instability. Because the rotational speed has obvious effect on the cross-coupled stiffness, it should be an important factor for choosing appropriate value of inlet circular velocity.

\section{References}

1. D. Childs, J. Scharrer. ASME Journal of Vibration, Acoustics, Stress, and Reliability in Design, 110, 11 (1988).

2. D. Childs, J. Scharrer. ASME Journal of Vibration, Acoustics, Stress, and Reliability in Design, 110, 7 (1988).

3. X. Li. International Journal of Computational Fluid Dynamics, 28, 10 (2014). 
4. X. Li, C. Gu, Computers \& Fluids, 86, 15 (2013).

5. X. Li, C. Gu, Journal of Computational Physics, 229, 13 (2010).

6. X. Li, J. Xu, C. Gu, Science in China - Series G: Physics Mechanics and Astronomy, 51, 11 (2008).

7. X. Li., X. Li. International Journal of Computational Fluid Dynamics, 30, 10 (2016).

8. C. Gu, F. Feng, X. Li, ASME Paper, No. GT2008-50203 (2008).

9. C. Gu, M. Chen, X. Li, ASME Paper, No. GT2008-50040 (2008).

10. X. Li, Y. Song, Z. Hao, C. Gu, Journal of Tribology - Transactions of the ASME, 134, 7 (2012).

11. Y. Song, X. Ren, C. Gu, X. Li, Journal of Tribology - Transactions of the ASME, 137, 9 (2015).

12. D. Huang, X. Li, Proceedings of the Institution of Mechanical Engineers - Part A: Journal of Power and Energy, 218, 7 (2004).

13. D. Huang, X. Li, Proceedings of the Institution of Mechanical Engineers - Part A: Journal of Power and Energy, 218, 7 (2004).

14. D. Huang, X. Li, Proceedings of the Institution of Mechanical Engineers - Part A: Journal of Power and Energy, 218, 11 (2004).

15. J. Moore, ASME Journal of Vibration and Acoustics, 125, 7 (2003).

16. T. Hirano, Z. Guo, R. Kirk, ASME Journal of Engineering for Gas Turbines and Power, 127, 7 (2005).

17. A. Pugachev, M. Deckner, ASME Paper, No. GT2010-22058 (2010).

18. A. Pugachev, U. Kleinhans, M. Gaszner, ASME Journal of Engineering for Gas Turbines and Power, 134,10 (2012).

19. Z. Li, J. Li, X. Yan, Journal of Vibration and Acoustics, 135, 9 (2013).

20. D. Childs, Turbomachinery rotordynamics: phenomena, modeling, and analysis (John Wiley \& Sons Press, New York, USA, 1993).

21. X. Li, C. Gu, J. Xu, Computers \& Fluids, 38, 8 (2009).

22. X. Li, C. Gu, Journal of Computational Physics, 227, 16 (2008).

23. C. Gu, W. Hao, X. Ji, X. Li, Energy, 112, 15 (2016).

24. J. Song, C. Gu, X. Li, Applied Thermal Engineering, 110, 9 (2017).

25. X. Ren, C. Gu, International Journal for Numerical Methods in Fluids, DOI: 10.1002/fld.4351. 